\title{
Long-term satisfaction of patients after laparoscopic and robotic-assisted hysterectomy
}

\author{
Georgios Gitas ${ }^{1}$ (D) I. Alkatout ${ }^{2} \cdot$ L. Proppe ${ }^{1} \cdot$ L. Hanker ${ }^{1} \cdot$ L. Allahqoli ${ }^{3} \cdot$ G. Grimbizis ${ }^{4} \cdot$ A. Rody $^{1} \cdot$ N. Werner ${ }^{1}$. \\ S. Sommer ${ }^{1}$.S. Baum ${ }^{1}$
}

Received: 9 February 2021 / Accepted: 6 December 2021 / Published online: 26 December 2021

(c) The Author(s) 2021

\begin{abstract}
Introduction Da-Vinci-Xi is the most recent device used in gynecologic robotic surgery. The aim of the present study was to compare the long-term satisfaction of patients who had undergone conventional laparoscopic hysterectomy or robotic assisted laparoscopic hysterectomy using the Da-Vinci-Xi surgical system.

Methods All hysterectomies performed at the University Hospital of Luebeck from 2018 to 2019 were reviewed. Postoperative outcomes were compared between women who had undergone total hysterectomy with da Vinci Xi $(n=42)$ or conventional laparoscopy $(n=97)$. Postoperative outcomes included pain, elimination of complaints after surgery, bladder function, sexual function, satisfaction with the cosmetic outcome, positive experiences after robotic surgery, and satisfaction with the surgeon's preoperative explanation. Obese patients were evaluated separately in a subgroup analysis.

Results Both groups had similar baseline characteristics and complication rates. Preoperative complaints subsided after surgery in a little more than $90 \%$ of patients. No significant differences were noted between groups in this regard $(p=0.262)$, or with reference to postoperative pain after one week $(p=0.866)$ and one month $(p=0.580)$, stress incontinence $(p=0.343)$, sexual function $(p=0.766)$ and the cosmetic outcome of the abdominal incisions $(p=0.273)$. The majority of patients who had undergone robotic surgery (96.8\%) would be willing to undergo the procedure again if necessary. The subgroup analysis of obese patients revealed no significant differences.

Conclusion The Da-Vinci-Xi device did not improve the long-term surgical satisfaction of normal-weight or obese patients who underwent hysterectomy compared with patients who underwent conventional laparoscopy performed by experienced laparoscopic surgeons.
\end{abstract}

Keywords Da Vinci Xi · Laparoscopic hysterectomy · Questionnaire $\cdot$ Robotic surgery $\cdot$ Patient satisfaction

Georgios Gitas

g.gitas@gmail.com

1 Department of Obstetrics and Gynecology, University Hospital of Schleswig Holstein, Campus Luebeck, Ratzeburger Allee 160, Haus A, 23538 Luebeck, Germany

2 Department of Obstetrics and Gynecology, University Hospital of Schleswig Holstein, Campus Kiel, Kiel, Germany

3 School of Public Health, Iran University of Medical Sciences (IUMS), Tehran, Iran

4 First Department of Obstetrics and Gynecology, Aristotle University of Thessaloniki, Thessaloniki, Greece

\section{Introduction}

Indications for robotic surgery have expanded considerably since FDA approval of the da-Vinci robot in 2005. In the United States, the use of robotic-assisted procedures in general increased from $1.8 \%$ in 2012 to $15.1 \%$ in 2018 [1]. Robotic-assisted laparoscopic hysterectomy is the most common robotic-assisted operation in gynecology, and the second most commonly performed surgery after cesarean section [2,3]. Da-Vinci-Xi, the most recent device in robotic surgery, is an advancement of the da Vinci robot in terms of form and functionality, including its targeting ability and the option of moving the robotic camera from port to port [4].

Extreme obesity, expressed as a body mass index (BMI) $\geq 40 \mathrm{~kg} / \mathrm{m}^{2}$, is emerging as a major public health problem; its prevalence has increased more than fourfold since the 
mid-1980s [5]. Obesity appears to be associated with a lower risk of morbidity in patients undergoing robotic-assisted gynecological surgery [6].

Despite the above-mentioned advantages, studies comparing the benefits and limitations of robotic-assisted hysterectomy with traditional laparoscopic hysterectomy remain inconclusive $[7,8]$. The existing studies show that patients who underwent surgery with the da-Vinci device had favorable outcomes in terms of quality of life and were generally pleased with their decision to undergo robotic-assisted surgery [9]. Studies concerning the satisfaction of patients with the robotic approach after 6 months or longer are still missing.

The aim of the present study was to compare long-term satisfaction in women who had undergone conventional laparoscopic surgery versus those who had undergone robotic-assisted total hysterectomy with Da-Vinci-Xi. The addressed aspects of satisfaction included sexual intercourse, postoperative pain, convalescence, incontinence, and cosmetic outcomes or scars. The surgical outcome of robotic hysterectomy in obese patients was analyzed separately.

\section{Materials and method}

A cohort study was carried out at the department of obstetrics and gynecology, University of Luebeck, from 2018 to 2019. Two-hundred women who had undergone hysterectomy by conventional laparoscopy were compared with one-hundred women who had undergone hysterectomy with the Da-Vinci-Xi device. The selections of the patients were based on the patient's wish to undergo robotic surgery or not and on our operational capacity'; thus it was limited for robotic surgery only once a week. The inclusion criteria were women who had undergone robot-assisted hysterectomy with Da-Vinci-Xi for benign indication (bleeding disorders, growth of uterus myomas, dyspareunia or abdominal pain) or early endometrial cancer. Patients with a tumor stage higher than FIGO I or with an additional operative procedure to hysterectomy, such as a prolapse operation or lymphadenectomy, were excluded from the study. The study was approved by the local ethics committee and our clinical protocols were in accordance with the German guidelines [10-13].

All surgeries were performed by three surgeons who had completed a course in robotic-assisted gynecologic surgery, and were also experienced in laparoscopic surgery (more than 500 laparoscopies). On the other hand, they had no experience of performing robotic surgery in humans prior to the study period. The surgeons' learning curve was completed in the middle of the study.

The preoperative explanation included a written description of the procedure and its risks. Patients were required to give their written consent. In the laparoscopic group, the abdominal cavity was accessed through the umbilicus and three trocars (5 and $10 \mathrm{~mm}$ ) were inserted at the lower quadrant of the abdomen. In the robotic group, the abdominal cavity was accessed through the umbilicus and an 8-mm trocar was inserted here. The remaining four trocars (three robotic $8-\mathrm{mm}$ trocars and one $10-\mathrm{mm}$ trocar for the assistant) were placed in a straight line at the level of the umbilicus.

Baseline characteristics (Table 1) were obtained from the patients' medical records. Postoperative outcomes included pain, elimination of complaints after surgery, bladder function, sexual function, satisfaction with the cosmetic outcome, positive experiences after robotic surgery, and satisfaction with the surgeon's preoperative explanation.

Pain was measured 1 week and 1 month after surgery. In order to avoid bias resulting from different cognitive levels, we used a numeric rating scale (NRS) for pain $(0=$ no pain, $10=$ worst pain imaginable) as recommended by the Initiative on Methods, Measurement and Pain Assessment in Clinical Trials (IMMPACT) [14]. Bladder function parameters included change of function after surgery and incontinence during physical activity. Sexual function consisted of four questions: sensation during intercourse after surgery, altered frequency of intercourse, reasons for the altered frequency of intercourse, and change in satisfaction during intercourse.

We used a questionnaire designed by the study group. The questions, which were reviewed by the consultant surgeons and validated for patient use, were based on two validated questionnaires: the Female Sexual Function Index (FSFI) $[15,16]$ and the health-related quality of life questionnaire by the EuroQol Group (EQ-5D) [17, 18]. Patients were asked to evaluate their long-term satisfaction with the procedure. Patients with partially filled questionnaires were excluded from the study.

A subgroup analysis was performed in patients with early endometrial cancer, benign disease, and obesity. According to the international classification, obesity is defined as a BMI $\geq 30 \mathrm{~kg} / \mathrm{m}^{2}$, and extreme obesity as a BMI $\geq 40 \mathrm{~kg} / \mathrm{m}^{2}$ [19].

All data were entered in the statistical software program IBM SPSS Statistics for Windows, version 21.0 (IBM Corp. 2012. Armonk, NY: IBM Corp.). Qualitative variables were described by frequency (percentage) and compared between groups with the Chi-square test or Fisher's exact test as appropriate. Normal distribution of data was assessed using a one-sample Kolmogorov-Smirnov test. The Mann-Whitney $U$ test was used to compare differences between two groups.

\section{Results}

One hundred and thirty-nine patients returned the completed questionnaire, which corresponds to a response rate of $46.3 \%$. The patients' mean age $( \pm S D)$ was $55.4 \pm 13.1$ years; 
Table 1 Demographic data of patients who had undergone surgery by the laparoscopic or robotic approach

\begin{tabular}{|c|c|c|c|c|}
\hline & Group I ( $n=97)$ & Group II $(n=42)$ & Total & $p$ \\
\hline Age (years) & $54.874 \pm 13.196$ & $56.450 \pm 13.185$ & $55.400 \pm 13.166$ & $\mathbf{0 . 4 9 5 ^ { \dagger }}$ \\
\hline BMI $\left(\mathrm{kg} / \mathrm{m}^{2}\right)$ & $29.596 \pm 8.21$ & $32.639 \pm 8.676$ & $30.522 \pm 8.441$ & $\mathbf{0 . 0 2 6}{ }^{\dagger}$ \\
\hline Obesity & & & & $\mathbf{0 . 2 3 3}^{\dagger \dagger}$ \\
\hline $25-29.9$ & $30(30.9 \%)$ & $11(26.2 \%)$ & $41(29.5 \%)$ & \\
\hline $30-34.9$ & $21(21.6 \%)$ & $10(23.8 \%)$ & $31(22.3 \%)$ & \\
\hline $39-39.9$ & $8(8.2 \%)$ & $7(16.7 \%)$ & $15(10.8 \%)$ & \\
\hline$>40 \mathrm{~kg} / \mathrm{m}^{2}$ & $9(9.3 \%)$ & $7(16.7 \%)$ & $16(11.5 \%)$ & \\
\hline Parity, $n$ & & & & $0.403^{\dagger \dagger \dagger}$ \\
\hline 0 & $28(30.1 \%)$ & $9(22.0 \%)$ & $37(27.6 \%)$ & \\
\hline $1-3$ & $62(66.7 \%)$ & $29(70.7 \%)$ & $91(67.9 \%)$ & \\
\hline$>3$ & $3(3.2 \%)$ & $3(7.3 \%)$ & $6(4.5 \%)$ & \\
\hline Menopause & $53(76.8 \%)$ & $25(78.1 \%)$ & $78(77.2 \%)$ & $\mathbf{0 . 8 8 4} 4^{\dagger \dagger}$ \\
\hline Diabetes & $12(12.4 \%)$ & $4(9.5 \%)$ & $16(11.5 \%)$ & $0.776^{\dagger \dagger \dagger}$ \\
\hline $\begin{array}{l}\text { ASA physical status classifica- } \\
\text { tion system }\end{array}$ & & & & $1.000^{\dagger+\dagger}$ \\
\hline 1 & $15(15.5 \%)$ & $3(7.3 \%)$ & $18(13.0 \%)$ & \\
\hline 2 & $58(59.8 \%)$ & $26(63.4 \%)$ & $84(60.9 \%)$ & \\
\hline 3 & $23(23.7 \%)$ & $12(29.3 \%)$ & $35(25.4 \%)$ & \\
\hline 4 & $1(1.0 \%)$ & $0(0 \%)$ & $1(0.7 \%)$ & \\
\hline Previous abdominal surgery & & & & $\mathbf{0 . 4 4 4}$ \\
\hline 0 & $52(54.2 \%)$ & $18(42.9 \%)$ & $70(50.7 \%)$ & \\
\hline 1 & $19(19.8 \%)$ & $13(31.0 \%)$ & $32(23.2 \%)$ & \\
\hline 2 & $14(14.6 \%)$ & $7(16.7 \%)$ & $21(15.2 \%)$ & \\
\hline 3 & $5(5.2 \%)$ & $2(4.8 \%)$ & $7(5.1 \%)$ & \\
\hline 4 & $4(4.2 \%)$ & $1(2.4 \%)$ & $5(3.6 \%)$ & \\
\hline Weight of the uterus ( $\mathrm{g}$ ) & $284.17 \pm 251.85$ & $177.00 \pm 102.158$ & $251.77 \pm 221.941$ & $0.229^{\dagger}$ \\
\hline Blood loss (g/dl) & $1.611 \pm 1.825$ & $1.419 \pm 0.86$ & $1.52 \pm 1.42$ & $\mathbf{0 . 5 1 2} \mathbf{1}^{\dagger}$ \\
\hline Intraoperative complications & $1(1.0 \%)$ & $1(2.4 \%)$ & $2(1.4 \%)$ & $\mathbf{0 . 5 1 5}$ \\
\hline Clavien-Dindo Grade IIIa & $7(7.2 \%)$ & $3(7.1 \%)$ & $10(7.2 \%)$ & $0.647^{\dagger \dagger \dagger}$ \\
\hline Postoperative complications & $3(3.1 \%)$ & $1(2.4 \%)$ & $4(2.8 \%)$ & $\mathbf{0 . 3 0 7} 7^{\dagger \dagger}$ \\
\hline Reoperation needed & $8(8.2 \%)$ & $3(7.1 \%)$ & $11(7.9 \%)$ & $0.563^{\dagger \dagger \dagger}$ \\
\hline
\end{tabular}

Continuous values are presented as means $\pm \mathrm{SD}$, and categorical variables are shown in numbers $(\%)$ Group I: Conventional laparoscopy, Group II: Robotic-assisted

$y$ year, $n$ number, $g$ gram, $B M I$ body mass index, $A S A$ American Society of Anesthesiologists, $g / d l$ grams per decilitre

${ }^{\dagger}$ Mann-Whitney $U$ test

${ }^{\dagger \dagger} \chi^{2}$ test

${ }^{\dagger \dagger}$ Fisher's exact test

$p$-value more than 0.05 is statistically not significant the youngest woman was 36 years old and the oldest 79 years. Approximately $77 \%$ of patients were postmenopausal. Thirty-one of them underwent surgery for early endometrial cancer. The mean weight of the uterus was $251.8 \mathrm{~g}$. The most common benign indications for surgery were bleeding disorders or uterine myomas (91.3\%).

Conventional laparoscopic hysterectomy was performed in 97 patients (Group I) and robot-assisted hysterectomy with Da-Vinci-Xi in 42 patients (Group II). The indications for hysterectomy were similar in both groups
( $p=0.641)$. Blood loss, intra- and postoperative injuries, and reoperation rates were similar in both groups. Patient characteristics were also similar and are summarized in Table 1.

With regard to the surgeons' learning curve (hysterectomies without follow-up were also included: 300 cases), the last 50 robotic surgeries were slightly shorter $(141.54 \pm 79.4$ vs. $144.38 \pm 86.57 \mathrm{~min})$ than the first 50 surgeries, but the difference was not statistically significant $(p=0.945)$ (Fig. 1). No significant differences were noted between 
groups with regard to postoperative pain after 1 week or 1 month, or any of the above-mentioned outcomes (Table 2). Preoperative complaints subsided after surgery in a little more than $90 \%$ of patients.

Significantly more patients in the robotic surgery group experienced a change in bladder function postoperatively (69.0 vs. $45.8 \%$ ). However, stress incontinence did not differ significantly between the two groups $(p=0.342)$. The rate of postoperative stress incontinence (Grade I-III) was $24.6 \%$ in the laparoscopic group and $18.0 \%$ in the robotic group. Data concerning grades of stress incontinence are shown in Table 2.

Only $55.2 \%$ of the patients were sexually active preoperatively. Approximately two-thirds of patients in both groups had consistent sexual function postoperatively. Satisfaction during intercourse was improved in $16.3 \%$, and reduced in $23.3 \%$. The most common reason for the altered frequency of intercourse was a change in the sensation of pleasure $(34.1 \%)$, followed by pain during intercourse $(7.3 \%)$. There was no significant difference in this regard between the laparoscopic and robotic group (Table 2).

In all, $93.5 \%$ of patients $(n=139)$ were satisfied with the cosmetic outcome of the abdominal incision. The percentages in the respective groups were $92.8 \%$ for laparoscopic surgery and $95.2 \%$ for robotic surgery $(p=0.723)$. Detailed interviews with patients revealed that only four patients in each group were dissatisfied with the numbers and locations of scars. The majority of patients who had undergone robotic surgery $(96.8 \%, n=30 / 31)$ would undergo the procedure again if necessary; the various reasons are shown in Table 2.
Furthermore, $90.5 \%$ of all patients were satisfied with the preoperative explanation of the operation. However, $40 \%$ (4/10) of the dissatisfied patients in the robotic group were poorly informed about the technology.

The subgroup analysis of patients who had undergone surgery only for early endometrial cancer or benign indications revealed no significant differences between the two subgroups. The results are shown in Table 3. Furthermore, we found no significant difference in patients with a BMI $>30 \mathrm{~kg} / \mathrm{m}^{2}$ or a BMI $>40 \mathrm{~kg} / \mathrm{m}^{2}$ in regard of postoperative outcomes and satisfaction.

\section{Discussion}

In the present study, we compared the long-term satisfaction of patients who had undergone hysterectomy using total laparoscopic surgery versus robotic surgery with Da-Vinci$\mathrm{Xi}$. The robotic approach yielded similar results as the laparoscopic procedure performed by well-trained surgeons in regard of postoperative satisfaction, sexual function, incontinence, cosmetic results, and pain. The majority of patients who had undergone robotic surgery were willing to undergo the procedure again if necessary.

Robotic-assisted laparoscopy is considered potentially superior to conventional laparoscopy in regard of postoperative pain. Studies assessing short-term perioperative parameters have reported that robotic-assisted laparoscopy is not associated with larger narcotic doses or greater postoperative
Fig. 1 Time taken by our team to perform robotic-assisted surgery (learning curve)

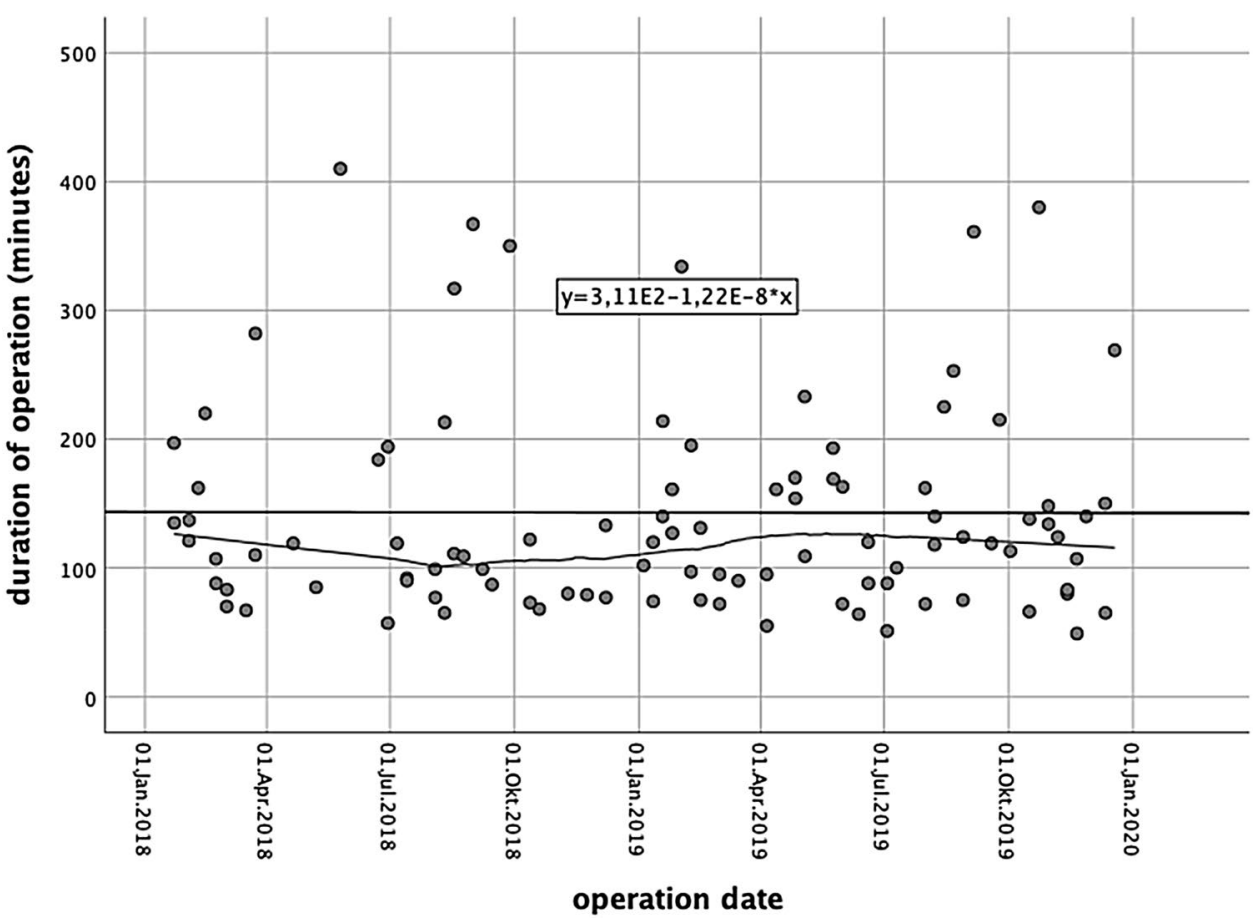


Table 2 Long-term postoperative satisfaction based on the questionnaire

\begin{tabular}{|c|c|c|c|c|c|}
\hline & & $\begin{array}{r}\text { Group I } \\
(\mathrm{n}=97)\end{array}$ & $\begin{array}{r}\text { Group II } \\
(\mathrm{n}=42)\end{array}$ & Total & $p$ \\
\hline $\begin{array}{l}\text { Postoperative pain } \\
\text { (after 1 week) }\end{array}$ & 129 & & & & $\dagger 0.866$ \\
\hline $1 / 10$ (minimal, very little pain) & & $15(16.3 \%)$ & $10(24.4 \%)$ & $25(18.8 \%)$ & \\
\hline $2 / 10$ & & $8(8.7 \%)$ & $5(12.2 \%)$ & $13(9.8 \%)$ & \\
\hline $3 / 10$ & & $21(22.8 \%)$ & $11(26.8 \%)$ & $32(24.1 \%)$ & \\
\hline $4 / 10$ & & $11(12.0 \%)$ & $4(9.8 \%)$ & $15(11.3 \%)$ & \\
\hline $5 / 10$ & & $9(9.8 \%)$ & $1(2.4 \%)$ & $10(7.5 \%)$ & \\
\hline $6 / 10$ & & $6(6.5 \%)$ & $3(7.3 \%)$ & $9(6.8 \%)$ & \\
\hline $7 / 10$ & & $5(5.4 \%)$ & $2(4.9 \%)$ & $7(5.3 \%)$ & \\
\hline $8 / 10$ & & $7(7.6 \%)$ & $2(4.9 \%)$ & $9(6.8 \%)$ & \\
\hline $9 / 10$ & & $5(5.4 \%)$ & $2(4.9 \%)$ & $7(5.3 \%)$ & \\
\hline 10/10 (very severe pain) & & $5(5.4 \%)$ & $1(2.4 \%)$ & $6(4.5 \%)$ & \\
\hline $\begin{array}{l}\text { Postoperative pain } \\
\text { (after } 1 \text { month) }\end{array}$ & 130 & & & & $\dagger 0.580$ \\
\hline $1 / 10$ (minimal, very little pain) & & $51(58.0 \%)$ & $27(64.3 \%)$ & $78(60.0 \%)$ & \\
\hline $2 / 10$ & & $12(13.6 \%)$ & $4(9.5 \%)$ & $16(12.3 \%)$ & \\
\hline $3 / 10$ & & $10(11.4 \%)$ & $2(4.8 \%)$ & $12(9.2 \%)$ & \\
\hline $4 / 10$ & & $7(8.0 \%)$ & $5(11.9 \%)$ & $12(9.2 \%)$ & \\
\hline $5 / 10$ & & $2(2.3 \%)$ & $2(4.8 \%)$ & $4(3.1 \%)$ & \\
\hline $6 / 10$ & & $3(3.4 \%)$ & $1(2.4 \%)$ & $4(3.1 \%)$ & \\
\hline $7 / 10$ & & $1(1.1 \%)$ & $0(0.0 \%)$ & $1(0.8 \%)$ & \\
\hline 9/10 & & $0(0.0 \%)$ & $1(2.4 \%)$ & $1(0.8 \%)$ & \\
\hline 10/10 (very severe pain) & & $2(2.3 \%)$ & $0(0.0 \%)$ & $2(1.5 \%)$ & \\
\hline Preoperative complaints subsided & 136 & & & & $\dagger 0.262$ \\
\hline after surgery & & $77(81.9 \%)$ & $36(85.7 \%)$ & $113(83.1 \%)$ & \\
\hline Yes & & $3(3.2 \%)$ & $0(0.0 \%)$ & $3(2.2 \%)$ & \\
\hline No, remained the same & & $2(2.1 \%)$ & $1(2.4 \%)$ & $3(2.2 \%)$ & \\
\hline No, significant pain & & $0(0.0 \%)$ & $1(2.4 \%)$ & $1(0.7 \%)$ & \\
\hline No, major mental health problems & & $11(11.7 \%)$ & $2(4.8 \%)$ & $13(9.6 \%)$ & \\
\hline $\begin{array}{l}\text { No preoperative complaints } \\
\text { Multiple answers }\end{array}$ & & $1(1.1 \%)$ & $2(4.8 \%)$ & $3(2.2 \%)$ & \\
\hline $\begin{array}{l}\text { Change in bladder function after } \\
\text { surgery }\end{array}$ & 138 & $44(45.8 \%)$ & $29(69.0 \%)$ & $73(52.9 \%)$ & $\dagger+0.012$ \\
\hline $\begin{array}{l}\text { Incontinence depending on the type } \\
\text { of activity }\end{array}$ & 71 & & $6(22.2 \%)$ & $16(22.5 \%)$ & $\dagger 0.343$ \\
\hline Grade 0 (not dependent) & & $10(22.7 \%)$ & $18(66.7 \%)$ & $41(57.7 \%)$ & \\
\hline Grade I (coughing/sneezing or & & $23(52.3 \%)$ & $0(0.0 \%)$ & $4(5.6 \%)$ & \\
\hline sports) & & $4(9.1 \%)$ & $3(11.1 \%)$ & $10(14.1 \%)$ & \\
\hline Grade II (in everyday activities) & & $7(15.9 \%)$ & & & \\
\hline $\begin{array}{l}\text { Grad III (even when lying or } \\
\text { sitting) }\end{array}$ & & & & & \\
\hline Sexually active preoperatively & 134 & $50(54.3 \%)$ & $24(57.1 \%)$ & $74(55.2 \%)$ & $\dagger 0.763$ \\
\hline $\begin{array}{l}\text { Sensation during intercourse } \\
\text { postoperatively* }\end{array}$ & 73 & & & & 0.766 \\
\hline Pain & & $5(10.0 \%)$ & $1(4.3 \%)$ & $6(8.2 \%)$ & \\
\hline Less intense sensation & & $3(6.0 \%)$ & $2(8.7 \%)$ & $5(6.8 \%)$ & \\
\hline Consistent & & $35(70.0 \%)$ & $15(65.2 \%)$ & $50(68.5 \%)$ & \\
\hline More intense sensation, improved & & $2(4.0 \%)$ & $2(8.7 \%)$ & $4(5.5 \%)$ & \\
\hline Multiple answers & & $5(10.0 \%)$ & $3(13.0 \%)$ & $8(11.0 \%)$ & \\
\hline Altered frequency of intercourse & 109 & & & & $\dagger+0.669$ \\
\hline Consistent & & $49(65.3 \%)$ & $21(61.8 \%)$ & $70(64.2 \%)$ & \\
\hline More frequent & & $7(9.3 \%)$ & $2(5.9 \%)$ & $9(8.3 \%)$ & \\
\hline Less frequent & & $19(25.3 \%)$ & $11(32.4 \%)$ & $30(27.5 \%)$ & \\
\hline $\begin{array}{l}\text { Reasons for the altered frequency } \\
\text { of }\end{array}$ & 41 & & & & $\dagger 0.325$ \\
\hline intercourse & & $1(4.0 \%)$ & $2(12.5 \%)$ & $3(7.3 \%)$ & \\
\hline Pain & & $8(32.0 \%)$ & $6(37.5 \%)$ & $14(34.1 \%)$ & \\
\hline Altered sensation of pleasure & & $0(0.0 \%)$ & $2(12.5 \%)$ & $2(4.9 \%)$ & \\
\hline No orgasm & & $1(4.0 \%)$ & $0(0.0 \%)$ & $1(2.4 \%)$ & \\
\hline $\begin{array}{l}\text { Sensation of descent } \\
\text { Multiple reasons }\end{array}$ & & $15(60.0 \%)$ & $6(37.6 \%)$ & $16(52.2 \%)$ & \\
\hline $\begin{array}{l}\text { Change in satisfaction during } \\
\text { intercourse }\end{array}$ & 86 & & & & $\dagger 0.348$ \\
\hline$\overline{\text { Consistent }}$ & & $35(61.4 \%)$ & $17(58.6 \%)$ & $52(60.5 \%)$ & \\
\hline More frequent / improved & & $11(19.3 \%)$ & $3(10.3 \%)$ & $14(16.3 \%)$ & \\
\hline Less frequent / reduced & & $11(19.3 \%)$ & $9(31.0 \%)$ & $20(23.3 \%)$ & \\
\hline
\end{tabular}


Table 2 (continued)

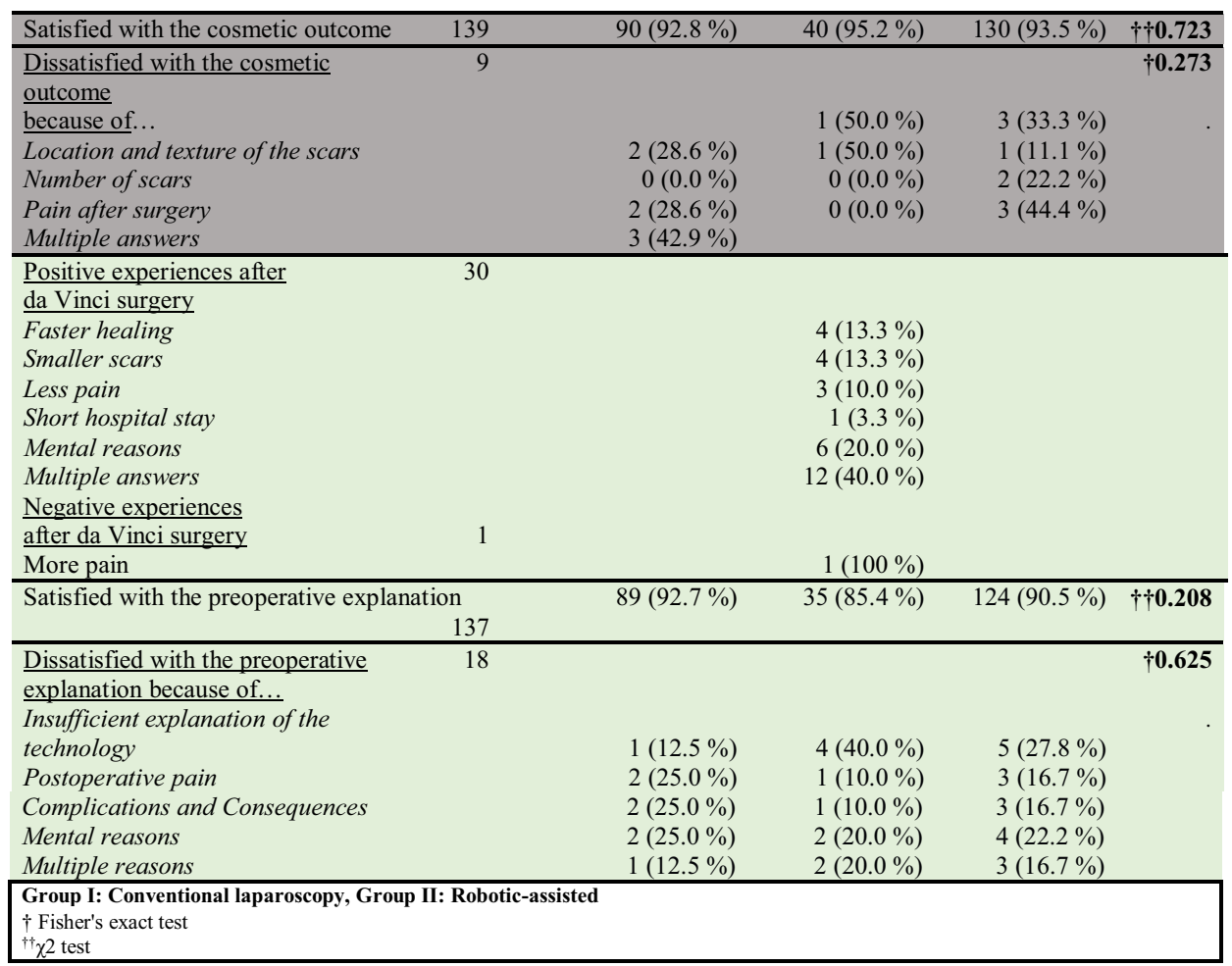

Color categories: pink: pain, yellow: continence, blue: sexual function, gray: cosmetic, green: satisfaction and preoperative explanation

Group I: Conventional laparoscopy, Group II: Robotic-assisted

${ }^{\dagger}$ Fisher's exact test

${ }^{\dagger} \chi^{2}$ test

pain compared to conventional laparoscopy [20, 21]. We used a numeric rating scale from 0 to 10 to assess pain and avoid bias resulting from different cognitive levels. We observed no significant difference among the two groups.

Quality of life at 6 months post-surgery was reported to be significantly better in patients who had undergone total laparoscopic hysterectomy compared to those who had undergone total abdominal hysterectomy [22]. However, patient satisfaction and quality of life have been scarcely investigated after robotic surgery. Two trials analyzed quality of life in patients who underwent conventional total laparoscopy hysterectomy or robotic-assisted hysterectomy [23, 24]. In 2013 Paraiso et al. randomized 62 women, followed them for 6 months after robotic and conventional laparoscopic surgery, and registered no significant difference in regard of quality of life [24]. In 2012, Sarlos et al. evaluated self-care, activities of daily living, pain, mobility, discomfort, depression, and anxiety in 96 patients after hysterectomy, and reported a significantly greater change in the preoperative to postoperative quality-of-life index in the robotic group compared to the laparoscopic group. However, the authors observed no difference in long-term outcomes [23]. Despite the ongoing development of robotic-assisted surgery, we registered similar results many years later.
The majority of our patients (90.5\%) were satisfied with the information they received prior to the operation. Satisfaction rates were slightly lower in the robotic group than in the laparoscopic group, but the difference was not statistically significant (85.4 vs. $92.7 \%$ ). However, the majority of dissatisfied patients lacked information about the technology, which is prone to rapid development and may aggravate the patients' anxiety. This issue should not be underestimated because thorough preoperative enlightenment enhances the patient's active participation in care and may well contribute to a rise in overall satisfaction [25].

More than a half of our patients were sexually active preoperatively. A significant number of them had trouble resuming sexual intercourse at least 6 months postoperatively (30\% of the laparoscopic, and $34.8 \%$ of the robotic group). Both groups had similar data in this regard. Our search of the published literature yielded no similar studies. In 2014, De La Cruz et al. analyzed postoperative sexual function and vaginal length in 38 patients who underwent total vaginal hysterectomy and in 46 who underwent robotic hysterectomy [26]. The authors observed no difference in sexual function between the two groups, but noted a greater reduction of vaginal length in the vaginal hysterectomy 
Table 3 Subgroup analysis of long-term postoperative satisfaction with reference to the indications for surgery (benign vs. early endometrial cancer), $\mathrm{BMI} \geq 30 \mathrm{~kg} / \mathrm{m}^{2}$ (obesity), and $\mathrm{BMI} \geq 40 \mathrm{~kg} / \mathrm{m}^{2}$ (extreme obesity)

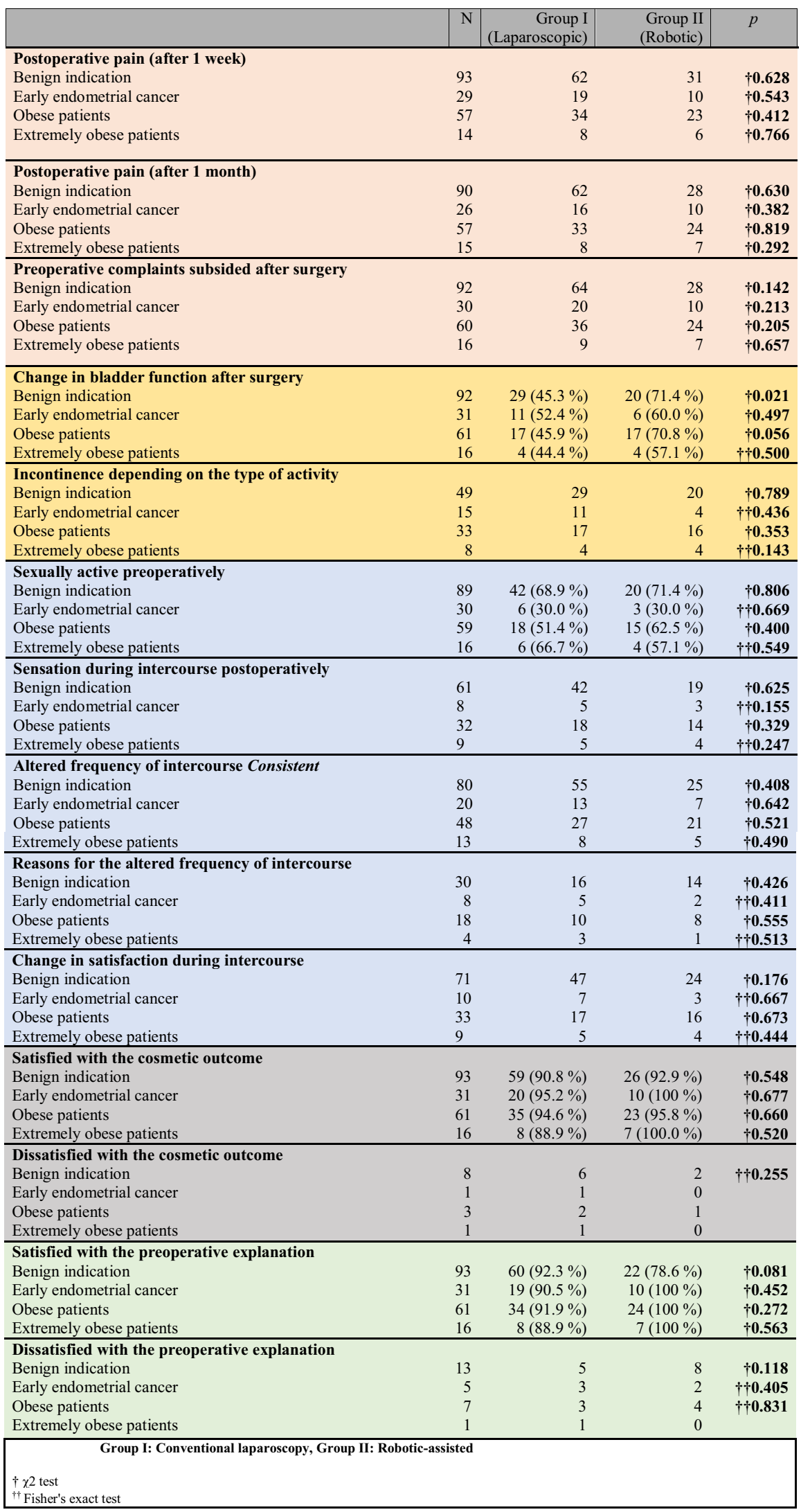


Table 3 (continued)

Color categories: pink: pain, yellow: continence, blue: sexual function, gray: cosmetic outcome, green: preoperative explanation

Group I: Conventional laparoscopy, Group II: Robotic-assisted

${ }^{\dagger} \chi^{2}$ test

${ }^{\dagger}$ Fisher's exact test

group. In 2016, Ercan et al. compared the vaginal and laparoscopic approach, and reported similar data [27].

Ercan et al. concluded that the absence of visible abdominal scars is probably associated with positive effects on the patients' self-esteem and quality of life [27]. We observed no significant difference between our groups concerning cosmetic results following the trocar incisions. More numerous trocars in a straight line at the level of the umbilicus were placed in the robotic group (Da-Vinci-Xi) in contrast to the laparoscopic group. Patient satisfaction with the cosmetic outcome was more than $92 \%$ in both groups. Elessawy et al. reported that $20 \%$ of patients were dissatisfied with the abdominal incision after total hysterectomy in the robotic group and only $2.7 \%$ in the laparoscopic group [28]. The authors attributed the difference to the rigidity of robotic trocars compared to the disposable trocar used in laparoscopy. However, a direct comparison of the latter study with ours is hindered by the fact that patients were contacted earlier (three weeks postoperatively), and the authors did not use the Da-Vinci-Xi system (incisions in a straight line). The development of a small single-incision port for robotic surgery may enhance satisfaction with the cosmetic outcome.

Significantly more patients experienced a change in postoperative bladder function in the robotic surgery group (69.0 vs. $45.8 \%$ ). Possibly the advantages of robotic surgery (3D techniques, finer tissue dissection) reduced the incidence of postoperative pelvic floor dysfunction by avoiding injury to local nerves and other pelvic floor structures. However, we focused on postoperative stress incontinence. With a prevalence of $14.3 \%$, stress incontinence is the most common complication in the lower urinary tract after hysterectomy [29]. On the other hand, a recent meta-analysis showed that hysterectomy for benign gynecological conditions does not increase the risk of adverse urinary symptoms [30]. We registered no statistically significant difference between groups concerning postoperative stress incontinence. However, postoperative stress incontinence rates were relatively high and slightly higher in the laparoscopic group (24.6\%) than in the robotic group (18.0\%).

The foremost limitation of the present study is that it was conducted at a single unit. The interval between surgery and the patients' response to the questionnaire may be viewed as a strength as well as a limitation of the study. Presenting the questionnaire to the patients after 6 months post-surgery may have led to bias. However, the aim of the study was to estimate long-term outcomes. A strength of the study was that we evaluated the most recent version of the robotic device, Da-Vinci-Xi, and also compared it directly with conventional laparoscopy. Furthermore, we compared the surgical outcome of laparoscopic approach with the robotic approach by trained laparoscopic surgeons without experience on robotic surgery, which according to our opinion, is an option and does not make our groups inhomogeneous but unique; thus most of the other institutions had already experienced robotic surgery before using Da-Vinci-Xi system. Our analysis revealed no significant difference in obese or extremely obese patients in regard of postoperative satisfaction. To the best of our knowledge, quality of life in obese patients after robotic hysterectomy has not been addressed in any published study.

However, we need further data on the use of robotic surgery in gynecology, especially with regard to long-term outcomes such as returning to activities of daily living. Further development of robotic surgery such as single port technique with smaller and flexible instruments and intraoperative high-quality navigation with imaging systems could open fascinating new avenues for improved minimally invasive surgery [31]. During this period, accumulating evidence has demonstrated the advantages and feasibility of vaginal natural orifice transluminal endoscopic surgery, which unfortunately is not suitable for complex gynecological operations $[32,33]$. In an attempt to overcome the shortcomings of the vaginal access, robotic surgery might be the solution.

\section{Conclusion}

Our data suggest that conventional total laparoscopic hysterectomy, performed by trained laparoscopic surgeons, is a safe procedure for a benign indication or for early endometrial cancer, and equivalent to robotic-assisted surgery in regard of postoperative patient satisfaction, sexual function, incontinence, cosmetic results, and pain. The majority of patients were willing to undergo robotic surgery again if necessary. The Xi-robot and the total laparoscopic procedure for hysterectomy yielded similar outcomes in obese patients, and no difference in patient satisfaction. Ongoing application and evaluation of the technology may be expected to optimize its function. The use of robotic surgery for a variety of gynecological diseases is yet to be clarified. Prospective 
multicenter randomized studies will be needed to determine the exact role of robotic surgery in gynecological surgery.

Acknowledgements None. All contributors met the criteria of authorship. There was no further contribution.

Author contributions Protocol/project development: GG, IA, AR, LP, NW. Data collection or management: GG, SB, NW, LP, LH. Data analysis: GG, IA, NW, SS. Manuscript writing/editing: GG, SB, AR, LH, IA, GG, LP, LA.

Funding Open Access funding enabled and organized by Projekt DEAL.

Data availability The datasets used and analyzed in the current study are available from the corresponding author on reasonable request.

\section{Declarations}

Competing interests The authors declare that they have no competing interests.

Ethics approval and consent to participate Approval was obtained from the ethics committee of the Medical Faculty of the University of Luebeck (approval number 20-174). Patient consent was obtained in writing. The investigation was performed in accordance with the Declaration of Helsinki.

Consent for publication Written patient consent was obtained.

Open Access This article is licensed under a Creative Commons Attribution 4.0 International License, which permits use, sharing, adaptation, distribution and reproduction in any medium or format, as long as you give appropriate credit to the original author(s) and the source, provide a link to the Creative Commons licence, and indicate if changes were made. The images or other third party material in this article are included in the article's Creative Commons licence, unless indicated otherwise in a credit line to the material. If material is not included in the article's Creative Commons licence and your intended use is not permitted by statutory regulation or exceeds the permitted use, you will need to obtain permission directly from the copyright holder. To view a copy of this licence, visit http://creativecommons.org/licenses/by/4.0/.

\section{References}

1. Sheetz KH, Claflin J, Dimick JB (2020) Trends in the adoption of robotic surgery for common surgical procedures. JAMA Netw Open 3(1):e1918911

2. Cohen SL, Ajao MO, Clark NV, Vitonis AF, Einarsson JI (2017) Outpatient hysterectomy volume in the United States. Obstet Gynecol 130(1):130-137

3. Gitas G, Alkatout I, Mettler L, Abdusattarova K, Ertan AK, Rody A et al (2020) Incidence of unexpected uterine malignancies after electromechanical power morcellation: a retrospective multicenter analysis in Germany. Arch Gynecol Obstet 302(2):447-453

4. Alkatout I, Mettler L, Maass N, Ackermann J (2016) Robotic surgery in gynecology. J Turk Ger Gynecol Assoc 17(4):224-232

5. Sturm R, Hattori A (2013) Morbid obesity rates continue to rise rapidly in the United States. Int J Obes (Lond) 37(6):889-891

6. Almeida OD Jr (2013) Robotic hysterectomy strategies in the morbidly obese patient. JSLS 17(3):418-422
7. Lonnerfors C, Reynisson P, Persson J (2015) A randomized trial comparing vaginal and laparoscopic hysterectomy vs robotassisted hysterectomy. J Minim Invasive Gynecol 22(1):78-86

8. Gitas G, Alkatout I, Proppe L, Werner N, Rody A, Hanker L, Pados G, Freytag D, Sommer S, Baum S (2021) Surgical outcomes of conventional laparoscopic and robotic-assisted hysterectomy. Int J Med Robot 17(3):e2225. https://doi.org/10.1002/rcs. 2225

9. Arms RG 3rd, Sun CC, Burzawa JK, Fleming ND, Nick AM, Rallapalli V et al (2015) Improvement in quality of life after robotic surgery results in patient satisfaction. Gynecol Oncol 138(3):727-730

10. Koh WJ, Abu-Rustum NR, Bean S, Bradley K, Campos SM, Cho KR et al (2018) Uterine neoplasms, version 1.2018, NCCN Clinical Practice Guidelines in Oncology. J Natl Compr Canc Netw 16(2):170-199

11. Emons G, Steiner E, Vordermark D, Uleer C, Bock N, Paradies $\mathrm{K}$ et al (2018) Interdisciplinary diagnosis, therapy and follow-up of patients with endometrial cancer. Guideline (S3-Level, AWMF Registry Number 032/034-OL, April 2018) - Part 2 with Recommendations on the Therapy and Follow-up of Endometrial Cancer, Palliative Care, Psycho-oncological/Psychosocial Care/Rehabilitation/Patient Information and Healthcare Facilities. Geburtshilfe Frauenheilkd 78(11):1089-1109

12. Gitas G, Freytag D, Allahqoli L, Baum S, Rody A, Maass N, Dinas K, Laganà AS, Moawad G, Sotiriadis A, Alkatout I (2021) Lymphadenectomy in endometrial cancer-achieving more with less? Minim Invasive Ther Allied Technol 13:1-9. https://doi.org/ 10.1080/13645706.2020.1868009

13. Gitas G, Proppe L, Alkatout I, Rody A, Kotanidis C, Tsolakidis D et al (2019) Accuracy of frozen section at early clinical stage of endometrioid endometrial cancer: a retrospective analysis in Germany. Arch Gynecol Obstet 300(1):169-174

14. Lawrie TA, Liu H, Lu D, Dowswell T, Song H, Wang L et al (2019) Robot-assisted surgery in gynaecology. Cochrane Datab Syst Rev 4:CD011422

15. Dworkin RH, Turk DC, Wyrwich KW, Beaton D, Cleeland CS, Farrar JT et al (2008) Interpreting the clinical importance of treatment outcomes in chronic pain clinical trials: IMMPACT recommendations. J Pain 9(2):105-121

16. Berner M, Kriston L, Zahradnik H-P, Harter M, Rohde A (2004) Validity and reliability of the German Female sexual Function Index (FSFI-d). Geburtshilfe Frauenheilkd 64(3):293-303

17. Gerstenberger EP, Rosen RC, Brewer JV, Meston CM, Brotto LA, Wiegel $M$ et al (2010) Sexual desire and the female sexual function index (FSFI): a sexual desire cutpoint for clinical interpretation of the FSFI in women with and without hypoactive sexual desire disorder. J Sex Med 7(9):3096-3103

18. Cabases J, Rabin R (2013) Chapter 1. Introduction. 2013 Sep 26. In: Szende A, Janssen B, Cabases J (eds) Self-reported population health: an international perspective based on EQ-5D [Internet], vol 2014. Springer, Dordrecht, NL

19. Sweeting HN (2007) Measurement and definitions of obesity in childhood and adolescence: a field guide for the uninitiated. Nutr J 6:32

20. Soliman PT, Langley G, Munsell MF, Vaniya HA, Frumovitz M, Ramirez PT (2013) Analgesic and antiemetic requirements after minimally invasive surgery for early cervical cancer: a comparison between laparoscopy and robotic surgery. Ann Surg Oncol 20(4):1355-1359

21. El Hachem L, Acholonu UC Jr, Nezhat FR (2013) Postoperative pain and recovery after conventional laparoscopy compared with robotically assisted laparoscopy. Obstet Gynecol 121(3):547-553

22. Janda M, Gebski V, Brand A, Hogg R, Jobling TW, Land R et al (2010) Quality of life after total laparoscopic hysterectomy versus 
total abdominal hysterectomy for stage I endometrial cancer (LACE): a randomised trial. Lancet Oncol 11(8):772-780

23. Sarlos D, Kots L, Stevanovic N, von Felten S, Schar G (2012) Robotic compared with conventional laparoscopic hysterectomy: a randomized controlled trial. Obstet Gynecol 120(3):604-611

24. Paraiso MF, Ridgeway B, Park AJ, Jelovsek JE, Barber MD, Falcone $\mathrm{T}$ et al (2013) A randomized trial comparing conventional and robotically assisted total laparoscopic hysterectomy. Am J Obstet Gynecol 208(5):368.e1-e7

25. Uldry E, Schafer M, Saadi A, Rousson V, Demartines N (2013) Patients' preferences on information and involvement in decision making for gastrointestinal surgery. World J Surg 37(9):2162-2171

26. De La Cruz JF, Myers EM, Geller EJ (2014) Vaginal versus robotic hysterectomy and concomitant pelvic support surgery: a comparison of postoperative vaginal length and sexual function. J Minim Invasive Gynecol 21(6):1010-1014

27. Ercan O, Ozer A, Kostu B, Bakacak M, Kiran G, Avci F (2016) Comparison of postoperative vaginal length and sexual function after abdominal, vaginal, and laparoscopic hysterectomy. Int J Gynaecol Obstet 132(1):39-41

28. Elessawy M, Schneekloth S, Gunther V, Maass N, Mettler L, Alkatout I (2020) Postoperative telephone-based questionnaire on quality of life after robotic-assisted laparoscopic hysterectomy versus conventional total laparoscopic hysterectomy. J Clin Med 9(9):2849. https://doi.org/10.3390/jcm9092849

29. Engh MA, Otterlind L, Stjerndahl JH, Lofgren M (2006) Hysterectomy and incontinence: a study from the Swedish national register for gynecological surgery. Acta Obstet Gynecol Scand 85(5):614-618

30. Duru C, Jha S, Lashen H (2012) Urodynamic outcomes after hysterectomy for benign conditions: a systematic review and metaanalysis. Obstet Gynecol Surv 67(1):45-54

31. Lagana AS, Garzon S, D'Alterio MN, Noventa M, Stabile G, Naem A et al (2020) Mini-laparoscopy or single-site robotic surgery in gynecology? Let's think out of the box. J Invest Surg 1-2

32. Buzzaccarini G, Stabile G, Torok P, Petousis S, Mikus M, Della Corte L et al (2021) Surgical approach for enlarged uteri: further tailoring of vNOTES hysterectomy. J Invest Surg 1-2

33. Buzzaccarini G, Noventa M, D'Alterio MN, Terzic M, Scioscia M, Schafer SD et al (2021) vNOTES hysterectomy: can it be considered the optimal approach for obese patients? J Invest Surg 1-2

Publisher's Note Springer Nature remains neutral with regard to jurisdictional claims in published maps and institutional affiliations. 